\title{
Laparaskopik Cerrahi Ve Ergonomi
}

\author{
Eşref Oğuz Güven, Taha Numan Akyol
}

Ankara Abdurrahman Yurtarslan Onkoloji Eğitim ve Araştırma Hastanesi, Üroloji Kliniği, Ankara

\section{Giriş}

L aparoskopik cerrahi 1980'li yıllardan sonra cerrahi pratiğine girmiştir. Bu cerrahinin temelleri ilk olarak Kelling tarafından 1901'de köpek peritonunun optikle gösterilmesiyle atılmış daha sonra çeşitli teknikler geliştirilmiş ve ilk başarılı laparoskopik kolesistektomi 1987 yılında Mouret tarafından uygulanmıştır (1). Ürolojide de; laparaskopinin kullanımı video yardımlı endoskopik cerrahiler ile başlamış ve ilk laparoskopik nefrektomi 1990'ların başında yapılmıştır. Ardından geçtiğimiz iki dekatta laparaskopik cerrahide önemli gelişmeler olmuş ve günümüzde laparoskopik operasyonlar pek çok operasyon tekniğinde, açık cerrahideki karşılıkları ile yer değiştirmiş ve altın standart haline gelmiştir (2).

Minimal invazif cerrahilerin uygulanmaya başlaması hastalara daha az ağrı, kısa hastanede kalış süresi ve daha iyi kozmetik sonuçlar gibi olumlu katkılar sağlarken; cerrahlar üzerinde olumsuz sonuçlar doğurabilmektedir. Bu cerrahileri uygulayanlarda kas iskelet sistemine ait bozukluklar olduğunu kanıtlayan pek çok çalışma bulunmaktadır (3-7). Özellikle operasyon sırasındaki postür bozukluğu ve hareket kabiliyetinin azalması nedeniyle omuz, bel ve sırtta ağrılar oluşmaktadır. Aynı zamanda laparaskopik cerrahi yapmayan cerrahlara göre yapanlarda karpal tünel sendromu, göz yorgunluğu ve servikal spondilozun daha sık görüldüğü bildirilmiştir (8). Ayrıca, laparoskopik el aletlerinin ergonomik olmayan başparmak kulplarından dolayı tenar nöropati olguları bildirilmiştir (9). Diğer taraftan yapılan çalışmalar, ergonomi kurallarına uyulduğunda laparaskopide sütur süresinde azalma olduğu ve cerrahlarda basınca bağlı kronik ağrıların giderilebilir olduğu gösterilmiştir $(10,11)$. Biz de bu derlemede laparoskopi ile ilişkili ergonomi prensiplerinden bahsedeceğiz.

\section{Ergonomi}

Ergonomi kelimesi Yunanca'da 'ergon' iş ve 'nomos' düzenleme anlamlarına gelen kelimeden türetilmiştir (1). İlk olarak sanayi sektöründe çalışan mühendisler tarafından 1949'da benimsenmiş ve kaliteyi artırmak amaçlı işçilerin çalışma ortam ve zamanlarının ayarlanması ile başlanmıştır. Çalışanların postür ve hareketlerine göre yeni yerleşimler yapılmıştır. Tıp alanında ise ergonomi prensiplerine çok uyulmamıştır. Son zamanlarda çalışan sağlı̆̆ı üzerine yapılan çalışmalar ile ergonominin farkına varılmış ve bazı ayarlamalar yapılmaya çalışılmıştır. Ergonomide cerrahi ekibin eğitimi, ameliyathanenin düzeni, güvenlik, verimlilik, cerrahi malzemelerin tasarımı önemli yer tutmaktadır.

\section{Ergonomik Sorunlar}

Laparaskopik cerrahide verimi etkileyen 2 önemli faktör fiziksel ve duyusal yani görsel eksen kaymasıdır. Açık cerrahide üç boyutlu görsellik ve dokunsal geri bildirim sayesinde cerrahın operasyon esnasında yoğun bir özgürlüğü bulunmaktadır. Ancak laparaskopide enstrümanlar cerrahın eli, kamera ise gözü gibi kullanılmaktadır. Bu nedenle derinlik algısında kayıp vardır. Sunulan sınırlı görüş nedeniyle periferal görme kaybı mevcuttur. Bu tarz kısıtlamalar cerrahın özgürlüğünde azalma ve operasyon esnasında daha dikkatli ve konsantre olması nedeniyle statik duruşa neden olmaktadır. Bu statik duruş kas ve tendonlarda laktik asit ve toksinler birikmekte bu nedenle ağrı ve yorgunluğa yol açmaktadır (12-14). Avrupa ve Amerika'da yapılan çalışmalarda statik duruşun laparaskopik cerrahlar üzerinde \%8-12 servikal ve üst ekstremite ağrısı, \%9-18 arasında ise kas spazmlarına yol açtığı gösterilmiştir (11). Fiziksel ergonomi cerrah için rahatlık sağlarken duyusal ergonomi (manipülasyon ve görsellik) hassasiyet, el becerisi ve güveni geliştirmektedir. Ergonominin bu iki unsuru birlikte güvenlik artışı, daha iyi sonuç ve streste azalmayı sağlamaktadır (15).

Laparaskopi ile ilgili temel ergonomik sıkıntı cerrahın statik duruşudur. Bu duruşu belirleyen 5 ana faktör bulunmaktadır: Enstrümanların tasarımı, monitörün konumu, masa yüksekliği, ayak pedallarının kullanımı ve ayak desteği. Bu faktörlerin en ergonomik haliyle ilgili çeşitli çalışmalar yapılmış ve Hollanda, Delft Teknoloji Üniversitesi'nde bu kriterlerle ilgili bir kılavuz oluşturulmuştur (16).

\section{Ergonominin Sağlanmasındaki Kriterler}

\section{Enstrümanlar}

Laparaskopi aletlerinin manipülasyonu sırasında el bileklerinde ağrı ve basıya bağlı parmaklarda ve el ayasında uyuşma gözlenmektedir. 'Society of American Gastrointestinal and Endoscopic Surgeons' (SAGES)' in 1996 da yaptığ çalışmada aletlere bağlı cerrahta yorgunluk, ağrı ve elde nöropraksi geliştiği gözlenmiştir. Yine aynı grup 149 cerrah üzerinde bir anket gerçekleştirmişler ve laparoskopik cerrahide 
tarafından görülmez. Bir ayak pedala basarken vücut ağırlığı diğer bacakta toplanır ve buna bağlı normalin dışında bir vücut duruşu meydana gelir. Bu da kas ağrılarına yol açabilir. Bunu engellemek için pedalın $25^{\circ}$ den fazla dorsal fleksiyona izin vermemesi, maksimum $10 \mathrm{~N}$ basınçla çalışması, basılması sırasında pedalın yer değiştirmemesi, görmeden de kontrol edilebilmesi, ayak pedalının boyunun $230-295 \mathrm{~mm}$ eninin $85-108 \mathrm{~mm}$, ayak parmağ aralığında olması gerekmektedir (16).

\section{Ayak desteği}

Cerrahi sırasında ayakta durmaya bağlı ayak kaslarının kasılmasıly büyük venöz damarlarda bası gelişir. Böylece ayak ağrıları ve uzun dönemde varis gelişebilir. Ayak desteği kullanımının kaslardaki kasılmaları \%60 azalttığı ve pelvise sabitlenerek omurlardaki baskıyı düşürdüğü gözlenmiştir. Cerrahi sırasında 780-1020 mm arasında ayak desteği kullanilabilmektedir (16).

$\mathrm{Bu}$ kriterlerin dişında hastanın ve cerrahi ekibin pozisyonu da önemlidir. Hastanın herhangi bir uzvu ekranı kapatmamalıdır. Hasta cerrahın önünde durmalıdır. Bazı kliniklerde, özellikle Avrupa'da, cerrah, hastanın bacakları arasına geçerek operasyonu yapar. Bu cerrahın alışkanlığ ve tercihidir. Cerrahın el, göz ve hedef organ aksı arasına hemşire veya asistan girmemelidir. Bu aksı herhangi bir enstrüman kapatmamalıdır (25). Portların yerleşimi diğer önemli husustur. Trokar yerleşimi ile ilgili ortak bir uygulama yoktur, cerrahın tercihi ve deneyimine bağlı değişmektedir. Çoğunlukla manüpilasyonun kolaylığı açısından 'triangulation' olarak isimlendirilen üçgen şekilde yerleştirilmektedir. Kameranın yerleştirildiği merkez portun hedef organa uzaklığı 15-20 cm olmalı, çalışma elemanları da merkez porta 5-7 $\mathrm{cm}$ aralıklarla yerleştirilmelidir. Portlar arasındaki mesafeye dikkat edilmesi uzun aletlerin rahat çalışmasına, bu şekilde 45-75’lik açıyla çalışmalarına olanak sağlar. Manasnayakorn ve ark.'larının hayvan modelleri üzerine yaptıkları çalışmalarda en iyi verimin 45-60lik açıyla sağlandığ $190^{\circ \prime} \mathrm{de}$ manipülasyonun aşırı kas yorgunluğu yaptığı gösterilmiştir (27). Dikkat edilmezse organa ulaşabilmek için karın duvarına basmak veya açı ayarlanamazsa manipülasyon için zor hareket yapmak gerekir buna bağlı el ve parmaklarda ağrı oluşabilmektedir (28).

\section{Sonuç}

Laparoskopik cerrahi, açık cerrahiye oranla daha fazla fiziksel ve mental yorgunluğa neden olmaktadır. Laparaskopi sonrası cerrahların \%30'unda rahatsızlık hissi gösterilmiştir. Boyun, sırt, el, el bileği ağrıları, spondiloz, tenosinovit, gözlerde yanma, göz kuruluğu, nöropraksi ve yorgunluk gibi pek çok sıkıntyla karşılaşmaktadırlar. Cerrahların büyük kısmı yanlış tekniklere bağlı nöropraksi ve sinir yaralanması gibi komplikasyonların geliştiğinin farkında değildir. Teknolojinin ilerlemesiyle el yardımlı laparaskopi, tek port laparaskopi, robot yardımlı laparaskopi gibi farklı modeller ortaya çıkmakta ve cerrahi daha kompleks hale gelmektedir. Tek port laparaskopide aletlerin abdominal bölgede çakışmaması için daha fazla manipülasyona ihtiyaç duyulmakta, bu da bilekte daha fazla ağriya yol açabilmektedir. Robotik cerrahi ise laparaskopiye oranla daha fazla hareket kabiliyetine sahip olduğundan ergonomik olarak daha avantajlıdır.
Mattern ve Waller ergonomiye daha uygun laparaskopi aletleri tasarlamışlardır. Üst kol aksında uygun çok fonksiyonlu kollar ile pronasyon ve supinasyona izin vererek etkinin doğrudan aktarılmasını sağlamaktadır (29). Sonuç olarak basit önlemler ile örnek olarak, kol hafif abdüksiyon, retroversion ve içe rotasyonda, dirsek yaklaşık $90-120^{\circ}$ de bükülü şekilde olmalıdır. Cerrah laktik asit birikimini engelleme için arada elini açıp kapatmalıdır. Derinlik algısı ile ilgili problemleri yenmek için 10-15X optik büyütme kullanılabilir (30). Operasyon sahası ve odasındaki küçük ayrıntılar da gözden geçirildiğinde cerrahi ekibin verimliliği ve konforu artacaktır.

\section{Kaynaklar}

1. Supe AN, Kulkami GV, Supe PA. Ergonomics in laparoscopic surgery. J Minim Access Surg. 6: 31-36, 2010.

2. Liang B, Qi L, Yang J. Ergonomin status of laparoscopic urologic surgery: survey results from 241 urologic surgeons in China. PLoS ONE 8:e70423, 2013.

3. Bagrodia A, Raman JD. Ergonomics considerations of radical prostatectomy: Physician perspective of open, laparoscopic and robot-assisted techniques. J Endourol. 23: 627-33, 2009.

4. Berguer R, Smith WD, Chung YH. Performing laparoscopic surgery in significantly more stressfull for the surgeon than open surgery. Surg Endosc. 15:1204-7, 2001.

5. Gofrit ON, Mikahail AA, Zorn KC. Surgeons' perceptions and injuries during and after urologic laparoscopic surgery. Urology 71:404-407, 2008

6. Reyes DA, Tang B, Cuschieri A. Minimal Access Surgery (MAS)- related surgeon morbidity syndromes. Surg Endosc. 20: 1-13, 2006.

7. Szeto GP, Ho P, TingAC. Work-related musculo skeletal symptoms in surgeons. J Occup Rehabil, 19: 175-184, 2009.

8. Hemal AK, Srinivas M, Charles AR. Ergonomic problems associated with laparoscopy. J Endourol. 15: 499-503,2001.

9. Uchal M, Brogger J, Rukas R. Inlineversuspistol grip handles in a laparoscopic simulators. A randomized controlled cross over trial. Surg Endosc. 16: 1771-3, 2002.

10. Joice P, Hanna GB, Cuschieri A. Ergonomic evaluation of laparoscopic bowel suturing. Am J Surg. 176:373-8, 1998.

11. Van Veelen MA, Meiier DW. Ergonomics and design of laparoscopic instruments: result of a survey among laparoscopic surgeons. J Laparoendosc Adv SurgTech A. 9: 481-9, 1999.

12. Kant IJ, de Jong LC, van Rijssen-Moll M, Borm PJ. A survey of static and dynamic work postures of operating room staff. Int Arch Occup Environ Health. 63:423-8, 1992.

13. Nguyen NT, Ho HS, Smith WD, Philipps C, Lewis C, De Vera RM, et al. An ergonomic evaluation of surgeons' axial skeletal and upper extremity movements during laparoscopic and open surgery. Am J Surg. 182:720-4, 2001.

14. Berguer R, Rab GT, Abu-Ghaida H, Alarcon A, Chung J. A comparison of surgeons' posture during laparoscopic and open surgical procedures. Surg Endosc. 11:139-42, 1997

15. Stylopoulos N, Rattner D. Robotics and ergonomics. SCNA. 83:1321-37, 2003. 
16. Van Veelen MA, Jakimowicz JJ, Kazemier G. Improved physical ergonomics of laparascopic surgery. Min Invas Ther \& Allied Tech. 13(3):161-6, 2004.

17. Berguer R. Surgical technology and the ergonomics of laparascopic instruments. Surg Endos12:458-62, 1998.

18. Majeed AW, Jacob G, Reed MW. Laparascopist's thumb: an occupational hazard. ArchSurg 128:357, 1993.

19. Neuhas SJ, Watson DI. Laparascopic surgeon's thumb is it a training phenomenon? Min Invas Ther \& Allied Tech. 6:31-32, 1997.

20. Horgan LF, O'riodon DC, Doctor N. Neuropraxia following laparascopic procedures: an ocupational injury. Min Invas Ther \& Allied Tech. 6:33-5, 1997.

21. Aitchinson LP, Flint J, Nesbitt-Hawes E et al. A feasibility study determining surgical setting. J Minim Invasive Gynecol 2015; Jan 28, doi:10.106/j.jmig.2015.01.022.

22. Patkin M, Isabel L. Ergonomics, engineering and surgery of endosurgical dissection. J Royal Coll Surg Edinburgh. 40: 120-32, 1995.

23. Tokar B. Laparoskopik Cerrahide Ön Hazırlık, Planlama ve Ergonomi. Eskişehir Osmangazi Üniv. Tıp Fakültesi. Çocuk Cerrahisi A.B.D

24. Erfenian K, Luks FI, Kurkchubasche AG. In-line image projection accelerates task performance in laparascopic apendectomy. J Pediatr Surg38:1059-62, 203.

25. Van Det MJ, Meijerink WJ, Hoff C. Optimal ergonomics for laparascopic surgery in minimally invasive surgery suites: a review and guidelines. Surg Endosc 23: 1279-85, 2009.

26. Berguer R, Smith WD, Davis S. An ergonomic study of he optimum operating table height for laparacopic surgery. Surg Endoscop16: 416-21, 2002.

27. Manasnayakorn S, Cuschieri A, Hanna GB. Ergonomic assessment of optimum operating table height for handassisted laparoscopic surgery. Surg Endosc.23:783-9, 2009

28. Trejo A, Jung MC, Oleynikov D, Hallbeck MS. Effect of handle design and target location on the insertion and aim with a laparoscopic surgical tool. Appl Ergon. 38: 745-53, 2007.

29. Mattern U, Waller P. Instruments for minimally invasive surgery: Principles of ergonomic handles. Surg Endoscop. 13: 174-82, 1999

30. Kant IJ, de Jong LC, vanRijssen-Moll M, Borm PJ. A survey of static and dynamic work postures of operating room staff. Int Arch Occup Environ Health.63: 423-8,1992.

\section{Yazışma Adresi:}

Eşref Oğuz Güven

Dr. Abdurrahman Yurtaslan Ankara Onkoloji Ĕ̆itim ve Araştırma Hastanesi,

Mehmet Akif Ersoy Mahallesi 13. Cadde No: 56 Yenimahalle, Ankara Tel: +903123360909

e-mail:oguz73tr@yahoo.com 